\title{
ESTUDO DE CASO: MINIMIZANDO LACUNAS DE CONHECIMENTOS BÁSICOS DOS DISCENTES INGRESSANTES DO CURSO DE ENGENHARIA QUÍMICA DA UNIFESSPA
}

\author{
Maristelly L. Souza - maristellylopes@ gmail.com \\ Ruthinéia J. A. do Nascimento - ruthineia.nascimento@unifesspa.edu.br \\ Vinicius Vescovi - v.vescovi@unifesspa.edu.br \\ Universidade Federal do Sul e Sudeste do Pará \\ Folha 17, Quadra 04, Lote especial, s/n ${ }^{\circ}$ \\ 68505-080 - Marabá - Pará
}

\begin{abstract}
Resumo: O curso de graduação em engenharia química da Unifesspa possui seis anos de criação, com apenas uma turma de discentes egressos e já é possível observar o fenômeno de evasão escolar. A evasão dos cursos de engenharia está associada a diversos motivos, mas um que se destaca é a dificuldade em acompanhar os conteúdos programáticos apresentados em sala de aula. Essas dificuldades se associam a lacunas de conhecimento oriundas do ensino médio e que podem ser minimizadas a partir de minicursos de nivelamento. As lacunas de conhecimento são as mais diversas e não se restringem apenas aos campos da física e da matemática. Sendo assim, este trabalho tem por objetivo averiguar quais as principais lacunas de conhecimento apresentadas pelos discentes do curso de engenharia química, quando na condição de alunos ingressantes, com o intuito de estruturar, gerenciar e executar a implantação de um minicurso de nivelamento para os discentes ingressantes do curso de graduação em engenharia química da Unifesspa. Por fim, concluiu-se que, os resultados obtidos ao final do evento, através de um questionário de feedback respondido pelos alunos, foram satisfatórios para a atualização de conhecimentos básicos dos alunos ingressantes.
\end{abstract}

Palavras-chave: Curso. Nivelamento. Conhecimentos Básicos. Engenharia.

\section{INTRODUÇÃO}

No decorrer dos seis anos de existência do curso de bacharelado em engenharia química da Universidade Federal do Sul e Sudeste do Pará (UNIFESSPA), já foi possível observar o fenômeno de evasão escolar, correspondente "a uma postura ativa do aluno que decide desligar-se por sua própria responsabilidade" (BUENO, 1993) ou até mesmo o desligamento à revelia do aluno, nos casos previstos no regulamento de graduação da instituição.

O grande número de alunos que se desvinculam de universidades públicas e demais instituições de ensino, está relacionado a diversos motivos, dentre os quais pode-se citar: a dificuldade de conciliar jornada de trabalho com jornada acadêmica, dificuldades financeiras, ausência de vantagem imediata com a titulação, problemas familiares (JACOB, 2000) e podemos acrescentar a este elenco, a dificuldade em acompanhar os conteúdos programáticos apresentados em sala de aula.

A dificuldade que os alunos apresentam em absorver os conhecimentos passados em sala de aula, em parte relaciona-se; em alguns casos, com o baixo interesse do aluno pela disciplina, mas também se deve, em boa parte dos casos, a falta de conhecimento básico que 
dê, ao discente, o suporte necessário para a aprendizagem dos conteúdos programáticos pertinentes ao ensino superior, em destaque os cursos de engenharia (TOSTA et al., 2017).

Muitos discentes ingressantes em cursos de engenharia apresentam dificuldades na área das ciências exatas; a saber química, física e matemática, isto acaba resultando em lacunas de conhecimento que afetam o desempenho, destes estudantes, em matérias essenciais para os cursos de engenharia, como as disciplinas das áreas de cálculo, cálculo aplicado, física e química (RODRIGUES et. al., 2012, FERREIRA et al., 2009, BARBETA e YAMAMOTO, 2002). Estas lacunas de conhecimento acabam resultando em problemas ainda maiores, tais como: reprovações, lacunas de conhecimento para as disciplinas do ciclo profissional e também a desistência, por parte do aluno, de finalizar o respectivo curso de graduação.

O preenchimento das lacunas de conhecimento mencionadas é de suma importância para aprimorar os conhecimentos profissionais internalizados pelos estudantes, ao longo do curso de graduação, mas não resolve o problema completamente. É necessário que se mude a visão profissional, destes alunos, pouco acostumados e/ou incentivados a serem personagens ativos no processo de aprendizagem (FERREIRA et al., 2001); ou seja, também é igualmente importante, que estes alunos compreendam que eles mesmos devem ser responsáveis pelo seu próprio aprendizado.

Dessa forma, com o intuito de minimizar as lacunas de conhecimento apresentada pelos discentes do curso de engenharia química, este trabalho tem por objetivo caracterizar e mitigar as principais lacunas relatadas pelos discentes "veteranos" através da criação do minicurso de conhecimentos básicos para os alunos ingressantes do curso de graduação em engenharia química da Universidade Federal do Sul e Sudeste do Pará (UNIFESSPA).

\section{METODOLOGIA}

A metodologia empregada no desenvolvimento deste trabalho teve por finalidade garantir a implantação de um minicurso de atualização de conhecimento básicos para os discentes ingressantes do curso de graduação em engenharia química da Unifesspa.

O minicurso de atualização de conhecimentos básicos ofertado foi intitulado: "Minicurso de nivelamento" associado ao projeto de extensão "NivelaEq".

A implantação do minicurso de nivelamento para o curso de graduação em engenharia química foi organizada em etapas, descritas como segue:

\section{ETAPA 1 - Captação de alunos voluntários}

- Captação de alunos voluntários para participação no projeto de extensão e atuação como tutores no curso de nivelamento.

- Divisão dos discentes voluntários em equipes.

\section{ETAPA 2 - Prospecção de dados}

- Reuniões colaborativas com os discentes integrantes do projeto, para a criação do questionário, sobre as dificuldades acadêmicas encontradas ao ingressar na Unifesspa.

- Realização do levantamento de dados, através do formulário do Google, com "alunos veteranos", sobre as dificuldades acadêmicas ao ingressar na Unifesspa.

\section{ETAPA 3 - Elaboração do plano de atividades}

- Construção do plano de atividades direcionadas às demandas expostas pela prospecção de dados (Etapa 3).

ETAPA 4 - Confecção de material de apoio ao projeto de extensão

- Elaboração da Logomarca do projeto de extensão.

- A partir dos dados coletados, na etapa 2, realizou-se a elaboração do material de apoio didático a ser utilizado no curso de nivelamento.

- Idealização e elaboração do kit de apoio didático ao projeto de extensão. 


\section{ETAPA 5 - Organização do evento}

- Planejamento e organização do evento, através do agendamento do espaço físico, confecção de material informativo, ações de divulgação do evento e cadastro do evento na plataforma sigeventos para emissão de certificados.

\section{ETAPA 6 - Realização do evento}

- Realização do evento na segunda semana do período letivo 2020.2 e avaliação do evento através de questionário (formulário do Google).

\section{ETAPA 7 - Avaliação do evento}

- Análise dos resultados obtidos após o final do primeiro semestre letivo, 2020.2, da UNIFESSPA.

\section{RESULTADOS E DISCUSSÕES}

O presente trabalho teve como meta norteadora, que a realização de um minicurso de atualização de conhecimentos básicos, possa contribuir de maneira significativa para o aumento na taxa de aprovação dos discentes ao longo dos semestres do curso de graduação em engenharia química, em especial, nos dois primeiros semestres letivos do referido curso de graduação. Com este intuito, ao longo do primeiro ano do projeto de extensão os objetivos específicos foram postos em prática e foram obtidos resultados satisfatórios e promissores.

\subsection{Prospecção de dados e perfil educacional dos discentes do curso de graduação em engenharia química da Unifesspa}

A etapa de prospecção de dados foi realizada a partir de um formulário do Google, criado com a finalidade de detectar as principais dificuldades enfrentadas pelos alunos do curso de graduação em engenharia química. O formulário foi distribuído pela internet através de grupos acadêmicos de WhatsApp e a divulgação do mesmo, foi realizada pelos integrantes do projeto de extensão em sala de aula, de forma presencial. Ao todo 70 discentes do curso de graduação em engenharia química responderam ao formulário proposto, correspondendo a 69\% dos "alunos veteranos" das turmas 2015, 2016, 2017, 2018 e 2019 com matrícula ativa no curso. O questionário contou com um total de dez perguntas. Os questionamentos foram de grande importância para determinar os principais tópicos a serem abordados no minicurso de nivelamento. $\mathrm{O}$ questionamento inicial abrangeu a vida acadêmica pregressa dos discentes, como pode ser averiguado na Figura 1.

Figura 1 - Questões 1(a), 2(b), 3(c) e 4(d) do questionário: "Questionário - minicurso de nivelamento".

Ao ingressar na Unifesspa, você sentiu que os seus conhecimentos pré-universitários em química, fisica, matemática e informática eram deficientes?

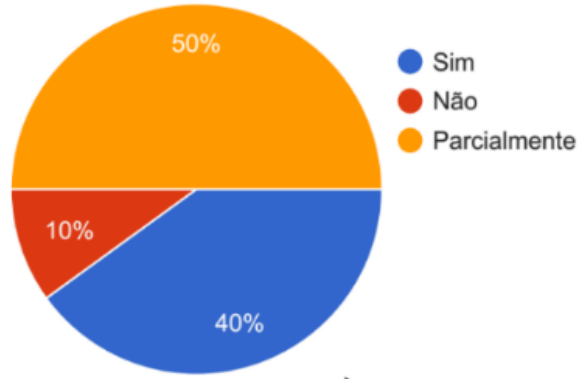

a)
Qual foi o grau de sua dificuldade em relação a base matemática ao ingressar no curso? (sendo 0 nenhuma e 5 máxima)

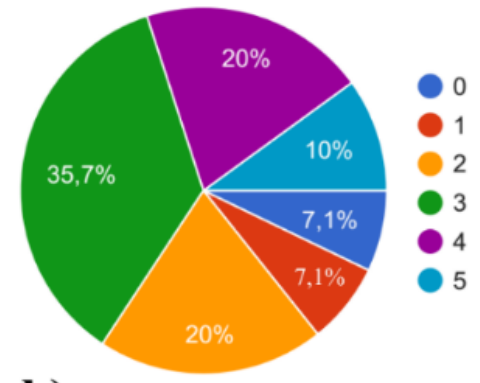

b) 


\section{COBENGE (C) COBENCE 2020

Em sua opinião, a dificuldade de assimilação do conteúdo, está vinculada à falta de domínio do conteúdo referente ao ensino médio?

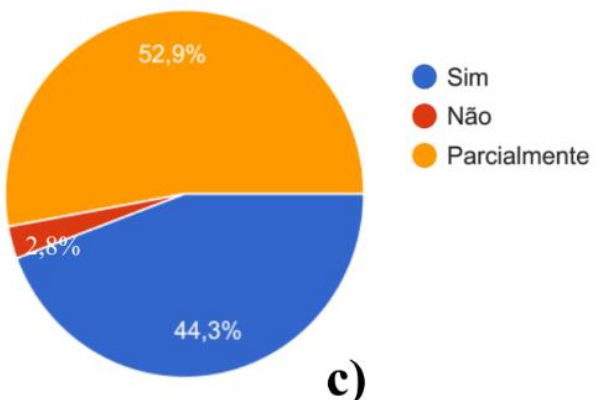

c)
Você gostaria de ter tido um curso de nivelamento acadêmico durante a primeira semana do seu curso de graduação?

d)

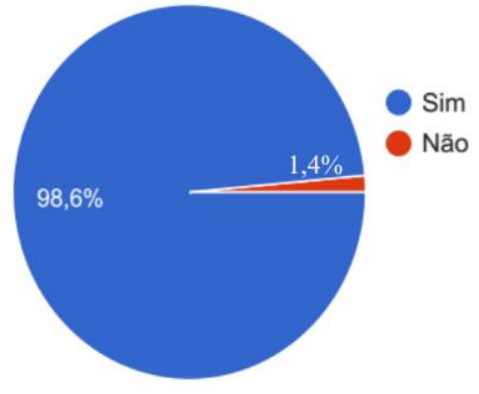

Fonte: "Questionário - minicurso de nivelamento"

Neste primeiro questionamento, Figura 1(a), apenas $10 \%$ dos discentes relataram que seus conhecimentos em física, química, matemática e informática não eram deficientes e dessa forma $90 \%$ dos discentes revelaram que consideravam que seus conhecimentos préuniversitários não foram suficientes para garantir uma boa base teórica para os conhecimentos universitários. Para mais de 97\% dos discentes, Figura 1(c), essa dificuldade está associada à falta de domínio de conteúdos inerentes ao ensino médio, especialmente em relação a sua base matemática, Figura 1(b). Diante deste cenário de lacunas de conhecimento, $98 \%$ dos entrevistados relataram que gostariam de ter tido a oportunidade de participar de um curso de nivelamento. Figura 1(d).

No segundo bloco do questionário, os discentes responderam questões referentes às disciplinas do primeiro ano do curso. Neste segundo questionamento, Figura 2, pode-se perceber que, para os estudantes do curso de graduação em engenharia química da Unifesspa; dentre as disciplinas: física, computação aplicada à engenharia química, cálculo e geometria analítica I, química geral e química geral experimental. 48,6\% dos alunos relataram que sentiram maior dificuldade em acompanhar a disciplina de Física, frente às demais disciplinas listadas, Figura 2(f). Ainda mais, 61,5\% dos estudantes relataram que a disciplina de física apresenta elevado grau de dificuldade, nível quatro e cinco, Figura 2(a).

Figura 2 - Questões 5(a), 6(b), 7(c), 8(d), 9(e) e 10(f) do questionário: “Questionário - minicurso de nivelamento".

Qual foi o grau de sua dificuldade em relação a FísICA ao ingressar no curso? (sendo 0 nenhuma e 5 máxima)

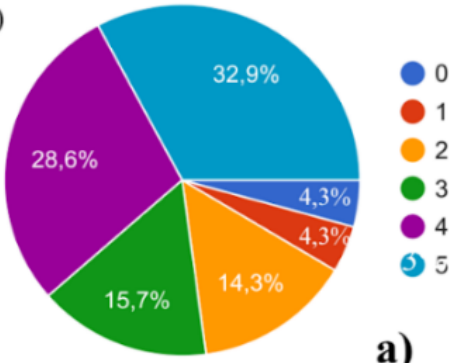

a)
Qual foi o grau de sua dificuldade em relação a COMPUTAÇÃO APLICADA À ENGENHARIA QUÍMICA ao ingressar no curso? (sendo 0 nenhuma e 5 máxima)

b)

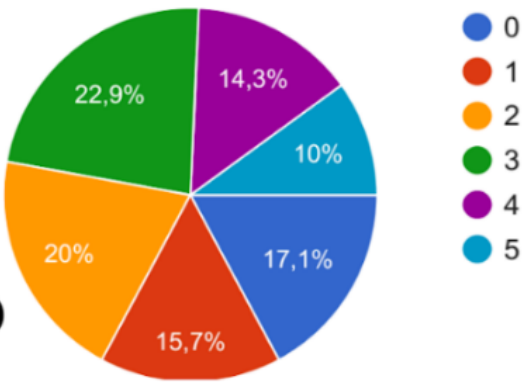


(C) COBENGE

"Os desafios para formar hoje o engenheiro do amanhã"
Qual foi o grau de sua dificuldade em relação a CÁLCULO E GEOMETRIA ANALÍTICA I ao ingressar no curso? (sendo 0 nenhuma e 5 máxima)

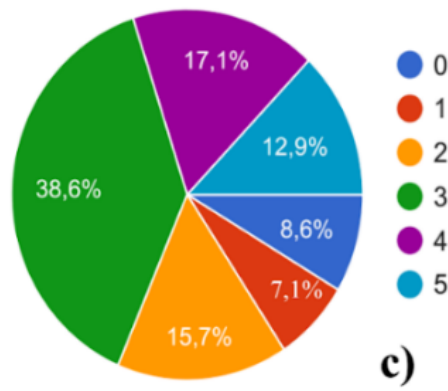

Qual foi o grau de sua dificuldade em relação a QUIMICA GERAL EXPERIMENTAL ao ingressar no curso? (sendo 0 nenhuma e 5 máxima)

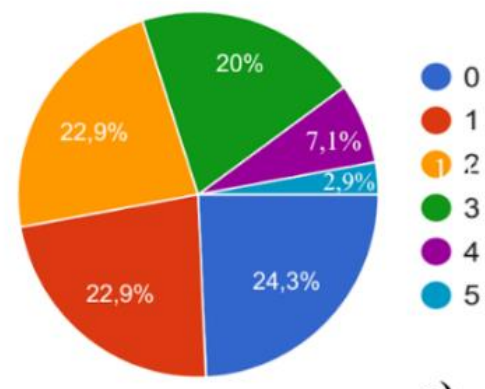

e)
Qual foi o grau de sua dificuldade em relação a QUÍMICA GERAL ao ingressar no curso? (sendo 0 nenhuma e 5 máxima)

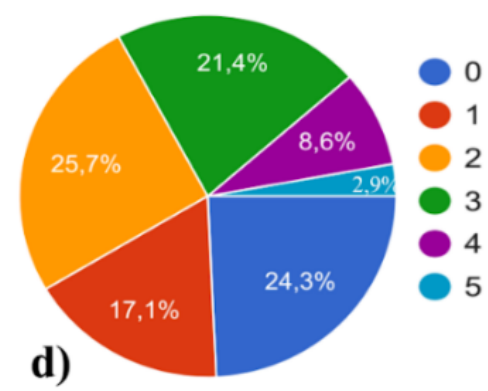

Em qual das disciplinas abaixo você sentiu maior dificuldade de assimilar o conteúdo exposto pelo professor?

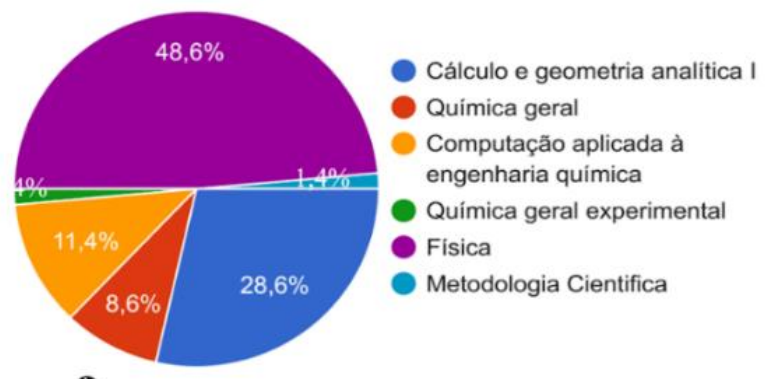

f)

Fonte: "Questionário - minicurso de nivelamento"

\subsection{Estruturação, execução e gerenciamento do minicurso de atualização de conhecimentos básicos dos discentes ingressantes da engenharia química da Unifesspa}

O trabalho foi iniciado com a captação de discentes do instituto de geociências e engenharias (IGE/Unifesspa), com a finalidade de implementação do minicurso de nivelamento da engenharia química. A equipe executora conta com dois professores coordenadores: Profa. Ruthinéia Jéssica Alves do Nascimento e o Prof. Vinicius Vescovi e 10 discentes do curso de graduação em engenharia química.

O gerenciamento e execução deste trabalho foi realizada através de reuniões presenciais realizadas nas salas 28, 29 ou 30 do Bloco 05 na Unidade II/Campus Marabá da Unifesspa, bem como através de grupo de conversa on-line criado no aplicativo WhatsApp e da conta Google $^{\circledR}$ nivelamento.equnifesspa@gmail.com criada com o intuito de gerenciamento do material de apoio do minicurso de nivelamento. Nas reuniões, foram decididas, em conjunto com todas as equipes, quais as melhores maneiras de alcançar os objetivos específicos do plano de atividades.

A divisão dos discentes, em equipes com objetivos próprios, mostrou-se uma ferramenta eficaz para a obtenção dos resultados almejados. As reuniões colaborativas, onde todos os integrantes do projeto podiam opinar e dar sugestões de forma igualitária, mostrou-se uma ferramenta importante para a execução das tarefas propostas, bem como mostrou-se eficaz na manutenção do engajamento dos discentes voluntários. 


\subsection{Realização do "Minicurso de Nivelamento para o curso de Engenharia Química"}

O evento foi realizado de 09 de março a 13 de Março de 2020, no turno da manhã das 8:00 às 12:00, no miniauditório do Bloco 05 na Unidade II/Campus Marabá da Unifesspa. A gestão do evento foi realizada mediante a utilização da plataforma SIGEventos da Unifesspa.

A divulgação do evento foi realizada de forma presencial, pelos integrantes do projeto, nos dias de cadastramento e matrícula dos discentes ingressantes da engenharia química, bem como através do perfil do projeto Nivelaeq na rede social Instagram.

$\mathrm{O}$ evento foi realizado segundo o cronograma, Figura 3. O minicurso foi organizado de maneira que cada equipe ficou responsável por um dos dias do minicurso de nivelamento e dessa forma pela revisão de uma parte dos tópicos abordados.

Figura 3 - Cronograma do Minicurso de nivelamento como divulgado no perfil @ nivelaeq do Instagram.

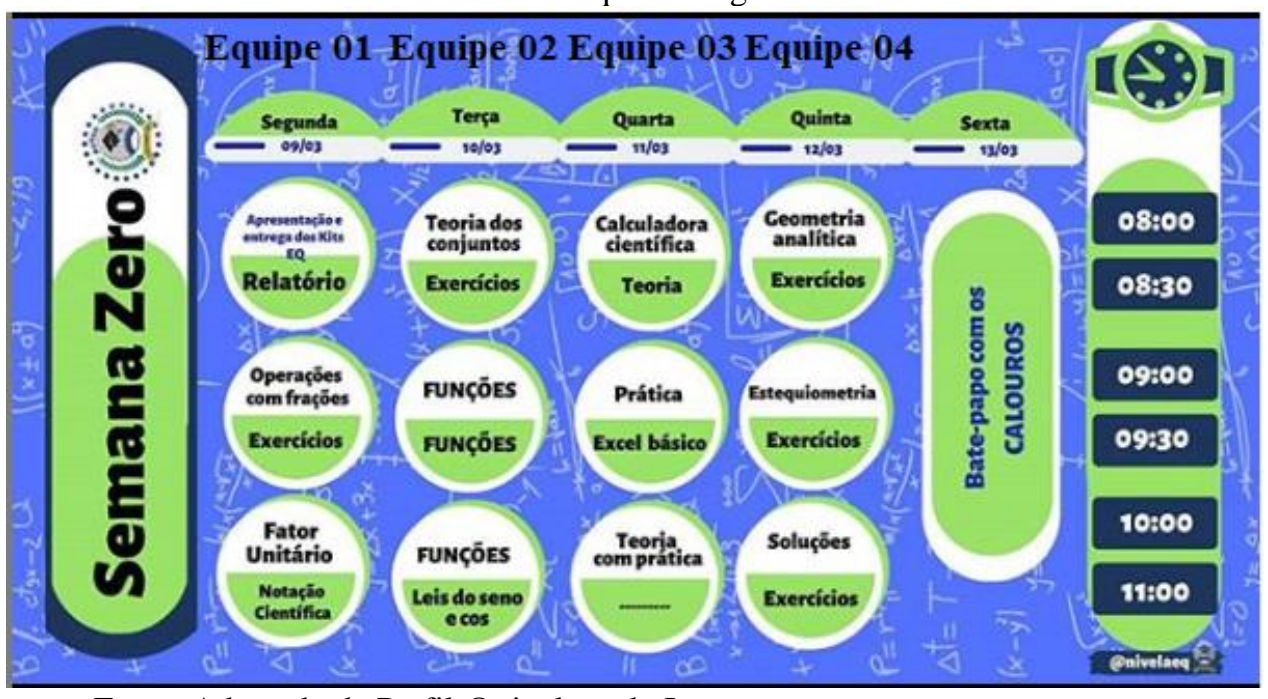

Fonte: Adaptado de Perfil @ nivelaeq do Instagram.

A divisão do minicurso de nivelamento por equipes possibilitou a participação de todos os integrantes na etapa de revisão de conhecimentos pré-universitários, bem como possibilitou maior interação entre os discentes ingressantes e os discentes "veteranos".

O último dia do minicurso foi voltado para uma roda de conversa entre os integrantes do projeto de extensão Nivelaeq e os participantes do minicurso de nivelamento, Figura 4, com a finalidade de proporcionar o encerramento do minicurso, bem como atrelar o momento a um feedback por parte dos discentes participantes do minicurso de nivelamento.

Figura 4 - Imagens da realização do minicurso de nivelamento - Roda de conversa.
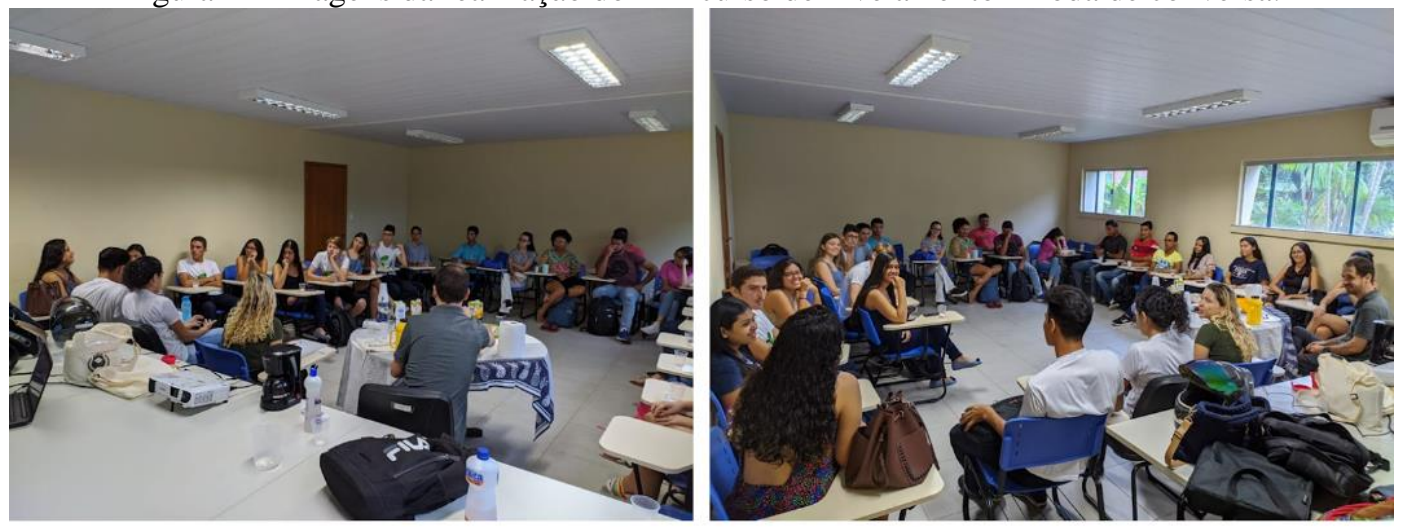
(C) COBENGE

"Os desafios para formar hoje o engenheiro do amanhã"
O1 a 03 de dezembro

\section{Evento On-line}
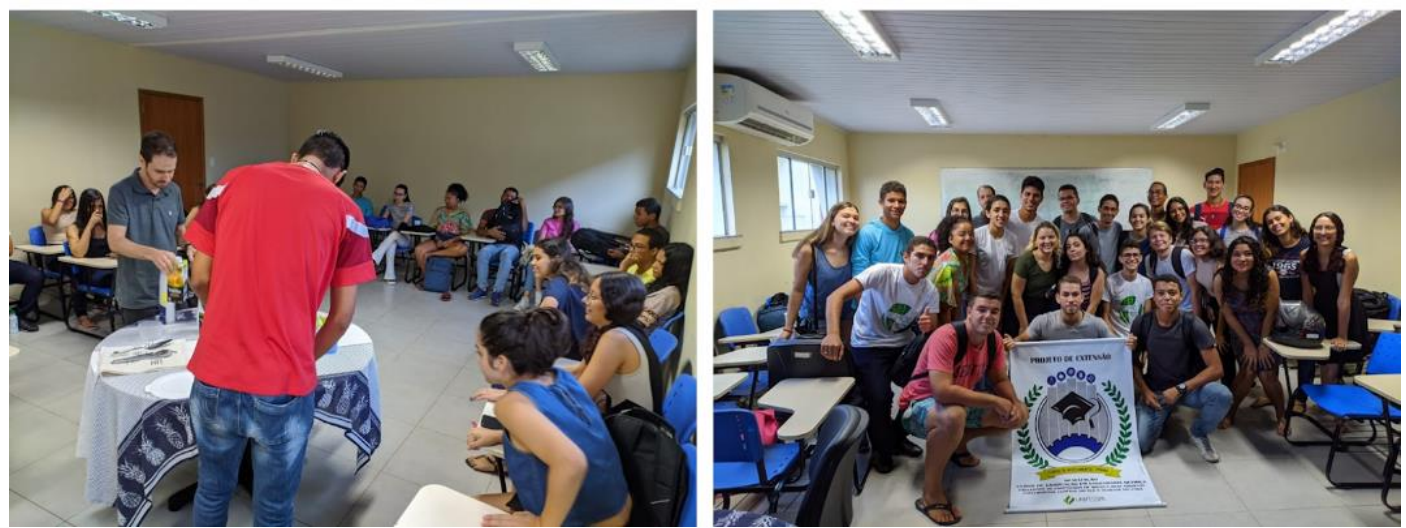

Fonte: Ferreira, K. A.[Imagem]. WhatsApp[NIVELAEQ]: 13 de março de 2020. 13:56. 1 mensagem de WhatsApp.

A Figura 5 apresenta imagens da realização do evento minicurso de nivelamento para a engenharia química.

Figura 5 - Imagens da realização do minicurso de nivelamento.

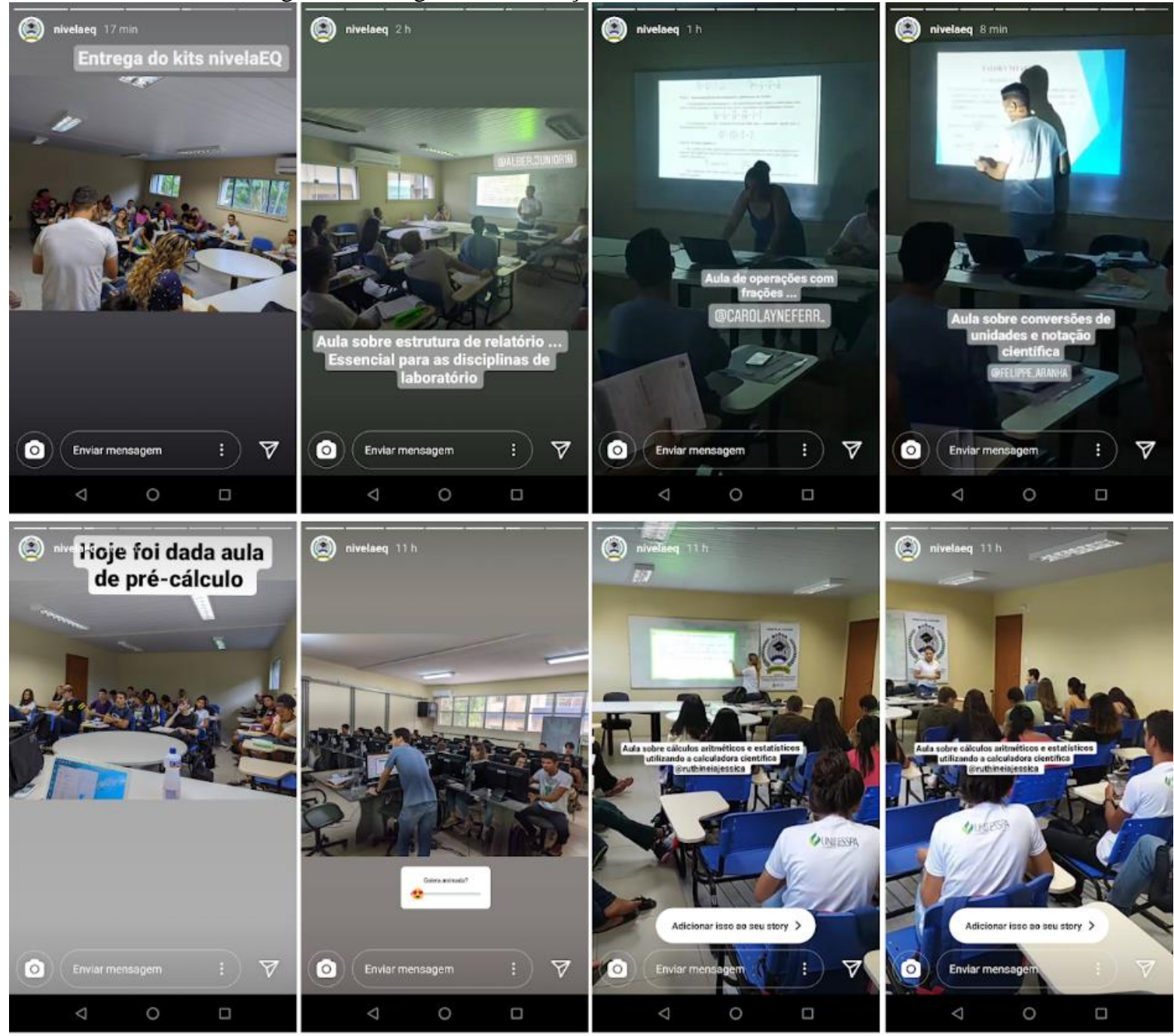

Fonte: Printscreen dos stories do perfil @nivelaeq do Instagram, entre os dias 09 de março de 2020 e 11 de março de 2020; Lima, L. B. P .[Imagem]. WhatsApp[NIVELAEQ]: 10 de março de 2020. 08:52. 1 mensagem de WhatsApp. 
O evento foi elaborado de maneira a permitir a emissão de certificados de participação do evento o que poderá comprovar horas complementares para os discentes ministrantes, bem como para os discentes participantes do minicurso de nivelamento.

\subsection{Feedback dos participantes do "Minicurso de Nivelamento para o curso de Engenharia Química"}

Ao final do último dia do evento, os estudantes responderam alguns questionamentos referentes ao minicurso de nivelamento, através de formulário do Google. De modo geral, o feedback dos alunos foi positivo, 100\% dos discentes acharam os assuntos abordados no evento úteis e claros. Para 95\% os exercícios propostos durante o minicurso contribuíram para a fixação do conteúdo, enquanto para mais $70 \%$ dos estudantes a metodologia de ensino teórica facilitou a compreensão do conteúdo. O principal problema apontado pelos discentes foi à falta de tempo, em especial para o conteúdo sobre editores de planilha. Ao final do questionário os alunos puderam expressar suas críticas e sugestões ao evento, Quadro 1.

Quadro 1 - Sugestões e críticas ao minicurso de nivelamento.

Qual a sua crítica e/ou sugestão a respeito da semana zero e em quê poderíamos melhorar?(15 respostas)

Poderia expandir a outras engenharias.

Deveriam expandir esse curso de nivelamento para outros cursos.

O curso está muito bom, mas o projeto deveria ser estendido para os outros cursos.

Poderiam expandir o curso a outras áreas da engenharia.

O curso de extensão poderia ser expandido para outros cursos.

Expandir para outros cursos da instituição.

Estender ou tornar ela integral facilitaria na teoria e prática de matérias mais detalhadas como geometria analítica, funções e com a calculadora científica e daria tempo de ter o curso completo do Excel básico.

Deveria abranger os outros cursos de engenharia da Unifesspa.

Melhorar teoria dos conjuntos e funções.

Só na questão da organização do tempo, e ser mais claro na resolução dos exercícios.

Deveria ser expandido para outras engenharias, visto a importância do calouro de engenharia saber o que ira ver inicialmente no curso.

Uma melhor preparação aos veteranos que irão ministrar a aula.

Marcar aulas extras para Excel básico e calculadora científica.

Mostra mais sobre as coisas do curso é conversar com os calouros suas dificuldades durante o curso. É um bate papo com os professores sobre as matérias e os projetos oferecidos. 
Poderíamos ter aula prática em laboratório. Como um experimento químico.

Fonte: "Questionário - minicurso de nivelamento"

\section{CONSIDERAÇÕES FINAIS}

Através das atividades realizadas, foi possível fazer o levantamento de dados da etapa 2 e detectar as principais dificuldades enfrentadas pelos discentes do curso de graduação em engenharia química, quando na condição de ingressantes. A etapa de prospecção de dados apresentou-se como uma etapa estratégica e de alta importância, pois a partir desta foi possível determinar os principais temas a serem abordados no evento e de fato implementar o primeiro minicurso de nivelamento do curso de graduação em engenharia química.

Os temas e didática abordados, no minicurso de nivelamento, mostraram resultados positivos e satisfatórios, por parte dos discentes participantes do evento, quanto a atualização de conhecimentos básicos nas áreas de cálculo, química e computação aplicada.

As metodologias sugeridas para estruturação, execução e gerenciamento do minicurso, mostraram-se promissoras e dessa forma demonstra a viabilidade de implantação de forma permanente do evento, de modo que possa abranger as lacunas de conhecimento em diversas áreas, não apenas nas áreas de matemática e física. Em feedback, os alunos ingressantes no curso de engenharia química, sendo os mesmos participantes do minicurso de nivelamento, sugeriram ainda a extensão do evento para outras engenharias, assim como a extensão do tempo de realização do mesmo. Por fim, concluiu-se que, os resultados obtidos ao final do evento, através de um questionário de feedback respondido pelos alunos, foram satisfatórios para a atualização de conhecimentos básicos.

\section{Agradecimentos}

Agradeço à Pró-Reitoria de Extensão e Assuntos Estudantis da Unifesspa, pelo fomento a prática da extensão universitária, à Prof ${ }^{a}$ Ruthinéia Jéssica Alves do Nascimento e Prof ${ }^{o}$ Vinicius Vescovi, pela orientação, e aos discentes Felippe Aranha Ferreira Silva, Carolayne Ferreira de Almeida, Alber Francisco Sales Teixeira Junior, Kaisson Almeida Ferreira, Ana Clara Ferreira de Sousa, Lorena Beatriz Pinho Lima, Francisco Neto Pinheiro dos Anjos, Rafael Melo dos Santos Costa e Ivanete Pereira Lima, que também compõem a equipe executora do projeto de extensão NivelaEq.

\section{REFERÊNCIAS}

Apresentadas em ordem alfabética e de acordo com a Norma ABNT - NBR 6023.

BARBETA, V. B.; YAMAMOTO, I. Dificuldades Conceituais em Física Apresentadas por Alunos Ingressantes em um Curso de Engenharia. Revista Brasileira de Ensino de Física, vol. 24, no. 3, 2002.

BUENO, José Lino Oliveira, (1993) Evasão Escolar. Paidéia (Ribeirão Preto) no. 5 Ribeirão Preto Aug. 1993.

FERREIRA, F. C.; CAÍRES, A. R. L.; SILVA, A. A.; OLIVEIRA, S. L. Diagnóstico de dificuldades conceituais em física apresentadas por acadêmicos ingressantes em cursos da UFGD. In: Encontro Nacional de Pesquisa em Educação em Ciências, VII Enpec, 2009, Florianópolis, Anais do VII Enpec. 
FERREIRA, J. A.; ALMEIDA, L. S.; SOARES, A. P. C. Adaptação académica em estudante do $1^{\circ}$ ano: diferenças do género, situação de estudante e curso. Psico-USF, vol. 6, n. 1, p. 01-10, 2001.

JACOB, C. A. R. A evasão escolar e a construção do sujeito / profissional em curso de Ciências Econômicas. Três Rios, 2000, 76p. Dissertação (Mestrado em Educação). Universidade Católica de Petrópolis. Petrópolis.

RODRIGUES, A. G.; TAVARES, A. S.; SOUSA, H. K. S.; JESUS, M. A.; SOUSA, T. A., GRANGEIRO, L. C.; ARAÚJO JÚNIOR, A. J. S. Curso de nivelamento de física elementar: um projeto inovador de aprendizagem na engenharia. In: Congresso Brasileiro de Educação em Engenharia, XL Cobenge, 2012, Belém, Anais do XL Cobenge.

TOSTA, M. C. R.; FORNACIARI, J. R.; ABREU, L. C. Por que eles desistem? análise da evasão no curso de engenharia de produção. Revista Produção Online. Florianópolis, v.17, n. 3, p. 1020-1044, 2017.

\title{
CASE STUDY: MINIMIZING BASIC KNOWLEDGE GAPS OF STUDENTS ENTERING THE CHEMICAL ENGINEERING COURSE OF UNIFESSPA
}

\begin{abstract}
The undergraduate course in chemical engineering at Unifesspa has six years of creation and with one only class of graduates, it is already possible to observe the phenomenon of school dropout. The scholar dropout in undergraduate engineering courses is associated with several reasons, but one stands out, that is the difficulty in following the course contents presented in classroom. These difficulties are associated with knowledge gaps arising from high school and which can be minimized by means of leveling short courses. Knowledge gaps are the most diverse and are not restricted to the fields of physics and mathematics. Therefore, this paper aims to find out what are the main knowledge gaps presented by students of the chemical engineering undergraduate course, when in the condition of incoming students, in order to structure, manage and execute the implementation of a leveling mini-course for students entering the undergraduate chemical engineering course at Unifesspa. Finally, it was concluded that the results obtained at the end of the event were satisfactory for updating basic knowledge of the incoming students.
\end{abstract}

Keywords: Course. Leveling. Basic Knowledge. Engineering. 